\title{
A Barotropic Vorticity Budget for the Subtropical North Atlantic Based on Observations
}

\author{
ISABELA AlEXANDER-Astiz LE BRAS \\ CASPO Division, Scripps Institution of Oceanography, University of California, San Diego, La Jolla, \\ California, and MIT-WHOI Joint Program in Physical Oceanography, Cambridge, Massachusetts \\ MAIKE SONNEWALD \\ Department of Earth and Planetary Sciences, Harvard University, and Department of Earth, Atmospheric and \\ Planetary Sciences, Massachusetts Institute of Technology, Cambridge, Massachusetts \\ JOHN M. TOOLE \\ Department of Physical Oceanography, Woods Hole Oceanographic Institution, Woods Hole, Massachusetts
}

(Manuscript received 8 May 2019, in final form 12 August 2019)

\begin{abstract}
To ground truth the large-scale dynamical balance of the North Atlantic subtropical gyre with observations, a barotropic vorticity budget is constructed in the ECCO state estimate and compared with hydrographic observations and wind stress data products. The hydrographic dataset at the center of this work is the A22 WOCE section, which lies along $66^{\circ} \mathrm{W}$ and creates a closed volume with the North and South American coasts to its west. The planetary vorticity flux across A22 is quantified, providing a metric for the net meridional flow in the western subtropical gyre. The wind stress forcing over the subtropical gyre to the west and east of the A22 section is calculated from several wind stress data products. These observational budget terms are found to be consistent with an approximate barotropic Sverdrup balance in the eastern subtropical gyre and are on the same order as budget terms in the ECCO state estimate. The ECCO vorticity budget is closed by bottom pressure torques in the western subtropical gyre, which is consistent with previous studies. In sum, the analysis provides observational ground truth for the North Atlantic subtropical vorticity balance and explores the seasonal variability of this balance for the first time using the ECCO state estimate. This balance is found to hold on monthly time scales in ECCO, suggesting that the integrated subtropical gyre responds to forcing through fast barotropic adjustment.
\end{abstract}

\section{Introduction}

In the subtropical North Atlantic, the ocean releases vast amounts of heat to the atmosphere (Kwon et al. 2010), and the regional circulation has been shown to impact oceanic heat storage, European climate, and biogeochemical cycling (Evans et al. 2017; Palter et al. 2005; Sutton and Dong 2012; Duchez et al. 2016). Understanding the dynamics of the subtropical North Atlantic circulation is hence a critical part of understanding the broader climate system and its response to change.

There is a significant history of elegant theories that describe ocean gyre dynamics. At the core of most of

Corresponding author: Isabela Alexander-Astiz Le Bras, ilebras@ ucsd.edu these theories is the fact that meridional variations in Earth's rotation constrain large-scale flows to be strongly zonal. The barotropic vorticity equation, which is the curl of the depth-integrated momentum equation, describes how large-scale meridional flows can develop despite this constraint (e.g., Hughes 2000). Sverdrup (1947) used the barotropic vorticity equation to demonstrate that zonal winds can drive meridional flows, and Stommel (1948) built on this to show that the anticyclonic wind pattern over subtropical gyres enabled depth-integrated southward flow throughout the gyre interior. Stommel proposed that this southward flow could be returned in an intense northward jet on the western side of the basin, where the change of planetary vorticity in this intense northward jet is balanced by bottom frictional torques. Munk (1950) extended this 
work by replacing linear bottom friction with lateral eddy viscosity, forming a theory that held even when bottom flows were weak.

For simplicity, these early theories were cast for a flat-bottomed ocean with vertical sidewalls. Around the same time, the importance of the response of flow to topography was recognized in the Antarctic Circumpolar Current. Munk and Palmén (1951) suggested that the "retarding pressure of submarine ridges," or form stress, balances the wind stress input of momentum. Holland (1972) later demonstrated the potential importance of sloping topography for gyre circulations by showing that the curl of form stress, also interpreted as a bottom pressure torque, leads to enhanced transport in winddriven western boundary currents.

Hughes and de Cuevas (2001) review the subsequent evolution of the barotropic vorticity framework in detail and suggest that the large-scale balance of gyre circulations is between the wind stress curl and bottom pressure torques. In this view, the broad equatorward depth-integrated flow forced by the wind in the interior of the gyre is returned poleward along the western continental slope without the need for frictional torques. Instead, the poleward return flow is supported by a torque associated with the normal pressure force along isobaths. Note that this framework does not explain the western intensification of gyres, or how the wind energy input to the ocean is dissipated (Jackson et al. 2006).

The balance between wind stress forcing and bottom pressure torques in subtropical gyres has been found to hold in numerical models across configurations and resolutions, suggesting that this large-scale balance is robust (Lu and Stammer 2004; Thomas et al. 2014; Yeager 2015; Schoonover et al. 2015; Sonnewald et al. 2019). The details of the vorticity budget at the western boundary do vary between models, however, and friction and nonlinear terms can play a significant role locally (Schoonover et al. 2015; Sonnewald et al. 2019). Most of the studies listed above focus on the time averaged vorticity balance over many years. Thomas et al. (2014) found that Sverdrup balance in the upper water column has an adjustment time of a few years, while Yeager (2015) found that the barotropic subtropical gyre can be spun up within a year. Hence, the adjustment time for the barotropic vorticity budget remains uncertain and has not been examined for subannual time scales. Furthermore, the large-scale vorticity balance found in these model studies has not been verified with observations.

One component of the large-scale vorticity budget that has been tested in observations is "Sverdrup balance," in which wind stress curl drives meridional flow. After Sverdrup's 1947 validation using an assumed level of no motion, there was debate in the literature over the relevance of Sverdrup balance, which centered around zonal hydrographic sections through the subtropical gyres in the Atlantic and Pacific at $24^{\circ} \mathrm{N}$ (Leetmaa et al. 1977; Wunsch and Roemmich 1985; Schmitz et al. 1992; Hautala et al. 1994). More recently, Sverdrup balance has been tested using Argo data (Gray and Riser 2014), and observationally constrained state estimate models (Wunsch 2011; Thomas et al. 2014). The consensus that emerged from this body of work is that Sverdrup balance generally holds in the interior of subtropical gyres, particularly in the top $1-2 \mathrm{~km}$, but breaks down as the western boundary is approached, where nonlinear and topographic effects become significant.

In this study, we bridge observations and models using a vorticity budget framework. We diagnose the barotropic vorticity balance for the subtropical gyre in the Estimating the Circulation and Climate of the Ocean (ECCO) observationally constrained state estimate, and complement this calculation with estimates of budget terms from hydrographic observations and wind stress products. Our primary goals are to 1) compare budget terms calculated from the observations, wind stress products, and the ECCO model and 2) examine the variability of the model budget terms on monthly time scales. In doing so, we seek to ground truth the model vorticity balance with observational evidence, and investigate adjustment time scales that have not been explored in this context.

Our model-data comparison is centered around the A22 World Ocean Circulation Experiment (WOCE) Hydrographic Program (WHP) section, which lies nominally along $66^{\circ} \mathrm{W}$ (Fig. 1). We calculate the net planetary vorticity flux across this section, which quantifies the difference in latitude of the depth-integrated flow in and out of the western subtropical gyre. The A22 section defines the boundary between our western and eastern subregions of the North Atlantic subtropical gyre. To provide additional points of comparison, we calculate the wind stress input of vorticity from two reanalysis and one climatological wind stress products over the subtropical North Atlantic to the east and west of A22.

We first review and discuss the barotropic vorticity budget framework, and describe how budget terms are calculated from each dataset (section 2). We then present the budget terms quantified from observational datasets: the wind stress forcing (section 3a) and planetary vorticity flux (section $3 b$ ). These are placed into the context of the full, time-varying vorticity budget in the ECCO state estimate (section 3c). Finally, we discuss the implications of our results for the emerging view of subtropical gyre dynamics (section 4). 


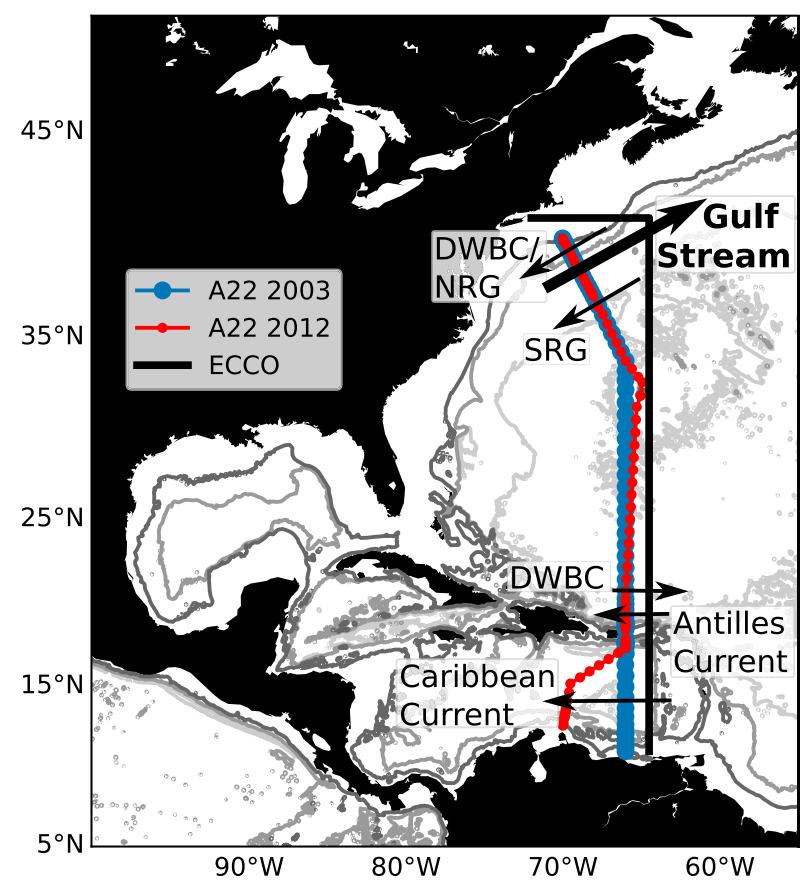

FIG. 1. Map of A22 cruise tracks, shown with major circulation features. Station positions of 2003 and 2012 occupations are denoted in blue and red, respectively. The thick black line shows the boundary used as a point of comparison with A22 in the ECCO state estimate. The 1000-, 3000- and 5000-m isobaths are denoted in shades of gray. DWBC: Deep Western Boundary Current, NRG: Northern Recirculation Gyre, and SRG: Southern Recirculation Gyre.

\section{Methods}

\section{a. Budget framework}

This work is focused around the barotropic vorticity equation, which is the curl of the depth-integrated momentum equations (e.g., Hughes 2000). We integrate the vertical component of the barotropic vorticity equation over an area of interest, which yields an equation for the evolution of the circulation of the depth-integrated flow $\tilde{\Gamma}$ :

$$
\begin{aligned}
\underbrace{\frac{\partial \tilde{\Gamma}}{\partial t}}_{\text {tendency term }}= & \underbrace{-\int f \mathbf{U} \cdot d \mathbf{n}}_{\text {planetary vorticity flux }}+\underbrace{\frac{1}{\rho} \iint \nabla \times \boldsymbol{\tau}_{w} \cdot d A}_{\text {wind stress forcing }} \\
& +\underbrace{\frac{1}{\rho} \iint\left(\nabla p_{b} \times \nabla H\right) d A}_{\text {bottom pressure torques }}+\underbrace{\mathscr{C}}_{\text {nonlinear torques }} \\
& +\underbrace{\mathscr{F}}_{\text {viscous stress torques }},
\end{aligned}
$$

where $\tilde{\Gamma}=\iint(\nabla \times \mathbf{U}) d A=\int \mathbf{U} \cdot d \mathbf{s} ; \mathbf{U}$ is the depthintegrated horizontal velocity vector, $\mathbf{U}=(U, V, 0)=$ $\left(\int_{-H}^{\eta} u d z, \int_{-H}^{\eta} v d z, 0\right) ; H(x, y)$ is the depth of the water column; $\eta(x, y)$ is the free surface height; $f$ is the Coriolis parameter, or planetary vorticity; $\rho$ is density; $p_{b}$ is bottom pressure (i.e., pressure at $z=-H$ ); and $\tau_{w}$ is the wind stress at the ocean surface; $(\nabla \times)$ is representative of the vertical component of the curl operator; $d \mathbf{n}$ is the unit vector normal to the boundary of the area; $d \mathbf{s}$ is the unit vector tangent to the boundary; and $d A$ is a unit area. The viscous stress torque term $\mathscr{F}$ includes torques due to vertical viscous stress at the ocean bottom (bottom friction) as well as lateral stress. In a numerical modeling context, subgridscale parameterizations of vertical and lateral stress are included in this term.

The nonlinear torque term $\mathscr{b}$ results from the advection term in the momentum equation. As shown in Schoonover et al. (2015), \& includes contributions from the curl of the vertically integrated momentum flux divergence, nonlinear contributions to vortex stretching, and transfer of vertical shear to barotropic vorticity. The time average of the curl of vertically integrated momentum flux divergence term includes contributions from Reynolds stresses. Le Bras (2017) shows that part of the vertically integrated momentum flux divergence can be written as the flux of relative vorticity $\left(\int \tilde{\zeta} \mathbf{U} \cdot d \mathbf{n}, \tilde{\zeta}=\nabla \times \overline{\mathbf{u}}, \overline{\mathbf{u}}=\mathbf{U} / H\right)$, and calculates the size of the analogous term from upper ocean observations in a depth-averaged vorticity framework. However the uncertainty in this term was deemed too large to diagnose from observations in the depthintegrated budget we consider here. While the nonlinear torque term can be important locally, its contribution has been found not to be significant on basin scales (Hughes 2000; Schoonover et al. 2015; Sonnewald et al. 2019).

Sverdrup balance describes a compensation between the planetary vorticity flux and wind stress forcing terms. It is more usually cast as $\beta V=\left(1 / \rho_{0}\right) \nabla \times \boldsymbol{\tau}_{w}$, where $\beta$ is the meridional gradient of the Coriolis parameter. Sverdrup balance is often invoked for the upper 1-2 km of the ocean, so in the context of this study we will refer to this relationship as "barotropic Sverdrup balance" to emphasize the fact that we integrate over the full water column. The planetary vorticity flux term (before area integrating) is equivalent to $\beta V$ when the divergence of the depth-integrated flow is zero, that is, $\nabla \cdot f \mathbf{U}=\beta V$ as $\nabla \cdot \boldsymbol{U}=0$.

Bottom pressure torques can be interpreted in a variety of ways. They can be thought of as variations in pressure gradient along bathymetric contours, or equivalently, as geostrophic bottom flows which cross isobaths and have an associated vertical velocity. Jackson et al. (2006) provide further explanation of bottom pressure torques as well as their link to 

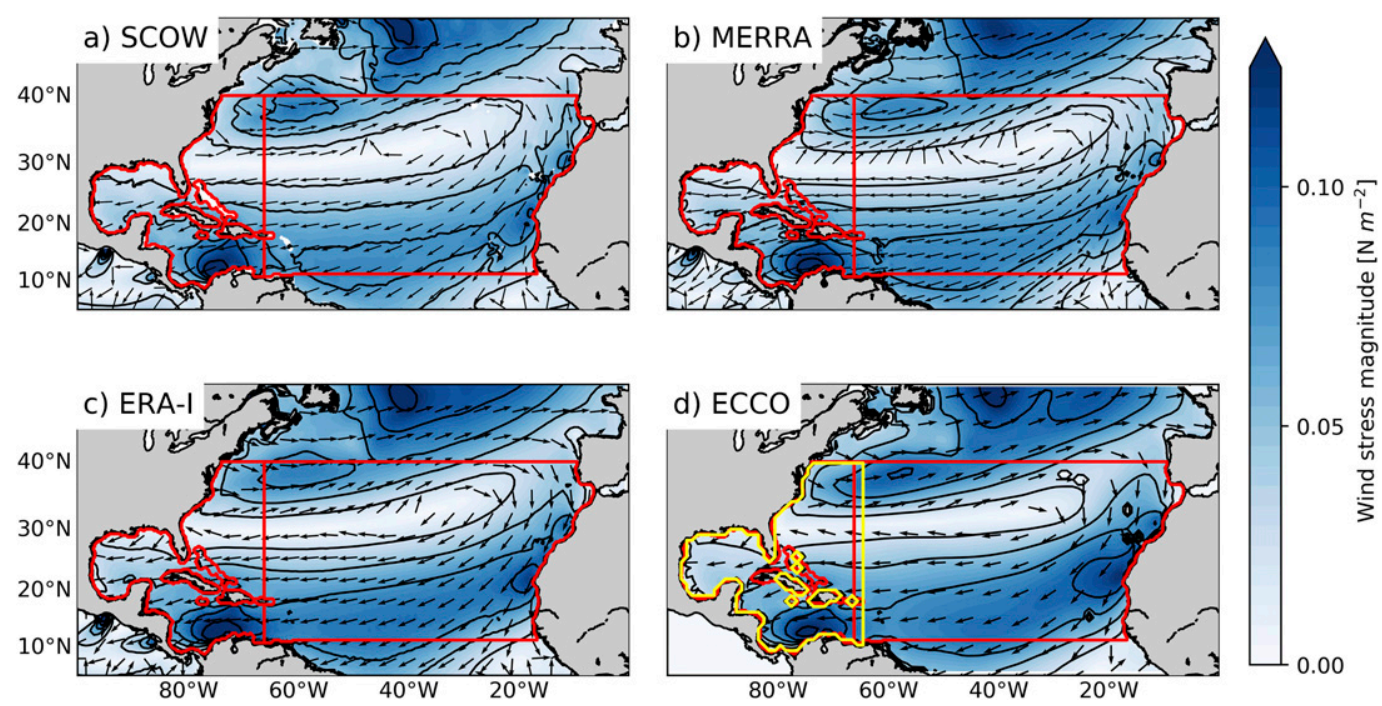

FIG. 2. Time-mean wind stress during the QuikSCAT era (September 1999-2009) from four different products. Contours reflect the wind stress magnitude, and arrows show direction. Contour lines are every $0.015 \mathrm{~N} \mathrm{~m}^{-2}$. (a) Scatterometer Climatology of Winds (SCOW). (b) NASA's Modern-Era Retrospective Analysis for Research and Applications (MERRA). (c) ECMWF's ERA-Interim Reanalysis (ERA-I). (d) ECCO state estimate. In (a)-(d) the red lines denote the boundaries within which the wind stress forcing terms are calculated. The yellow boundaries in (d) are those defined using the ECCO grid for the western region. An arrow is plotted every 15 data points in (a), and every 5 data points in the remaining panels.

potential vorticity. As they explain, bottom pressure torques do not force oceanic flows in the same way that wind stress forcing does, but rather are a "measure of the topographic steering of the flow." In a barotropic ocean with homogeneous density, bottom pressure torques represent the crossing of $f$ contours by the depth-integrated flow in order to align with $f / H$ contours. However, in a realistic ocean this is complicated by stratification (Holland 1972; Yeager 2015).

Our focus is on the subtropical gyre between $11^{\circ}$ and $40^{\circ} \mathrm{N}$ (Fig. 2). We calculate budget terms for western and eastern subregions of the subtropical gyre, which we define relative to the position of the A22 hydrographic section (Fig. 1).

\section{b. Wind stress datasets}

We estimate the wind stress forcing term in Eq. (1) for the western and eastern subregions of the subtropical gyre from the Scatterometer Climatology of Ocean Winds (SCOW), NASA's Modern-Era Retrospective Analysis for Research and Applications (MERRA), and the European Centre for Medium Range Weather Forecast's (ECMWF) interim reanalysis (ERA-Interim). SCOW is based on 10 years of Quick Scatterometer (QuikSCAT) observations, from September 1999 to 2009. SCOW has been smoothed using harmonic analysis in an attempt to remove extreme events and is said to represent a "typical" annual cycle (Risien and Chelton 2008), while MERRA and ERA are true time series including synoptic, seasonal, and interannual variability. The SCOW data are provided on a $0.25^{\circ}$ grid. MERRA and ERA are satellite era reanalyses (from 1979 onward) and have $0.6^{\circ} \times 0.5^{\circ}$ and $0.7^{\circ}$ resolution, respectively (Rienecker et al. 2011; Dee et al. 2011; ECMWF 2012).

To calculate the wind stress forcing from the SCOW, MERRA, and ERA wind stress data products, we interpolate each product to the SCOW grid, take the curl of the wind stress and integrate within an area defined by the coastlines in the SCOW climatology, $11^{\circ} \mathrm{N}, 40^{\circ} \mathrm{N}$, and $66^{\circ} \mathrm{W}$ (Fig. 2). We use a constant reference density for this calculation, $\rho \rightarrow \rho_{0}=1027 \mathrm{~kg} \mathrm{~m}^{-3}$. Time averages of the MERRA and ERA wind stress products are taken over the QuikSCAT era to facilitate comparison with SCOW. We detail the sensitivity of our results to our calculation methods in section $3 a$.

\section{c. A22 hydrographic data}

We calculate the planetary vorticity flux term in Eq. (1) for the western subtropical gyre from A22 hydrographic data (Fig. 1). Section A22 was occupied in 2003 (23 October-13 November) and in 2012 (24 March-17 April). The A22 section is ideal for this calculation because, with the American continent, it creates a closed volume, so that the net volume transport 
across the section can be assumed to be zero and physical meaning can be attributed to the planetary vorticity flux across it.

We use full-depth A22 velocity fields that are the result of an inverse calculation reported by CasanovaMasjoan et al. (2018). The authors calculate the geostrophic velocity between pairs of stations from the CTD (conductivity, temperature, depth) data, referenced to the station pair averaged across-track velocity from LADCP (lowered acoustic Doppler current profiler) observations. These velocities are used as the input to an inverse model constrained by mass and silica conservation in 17 neutral density layers based on traditional water mass definitions. The Ekman transport is calculated from National Centers for Environmental Prediction (NCEP) wind stress at each station pair and included in the shallowest transport layer (CasanovaMasjoan et al. 2018). Note that Casanova-Masjoan et al. (2018) take density variations into account and balance mass across the section, while we make the Boussinesq approximation and invoke a volume balance across the section. We apply a constant velocity correction to the Casanova-Masjoan et al. (2018) data product so that volume transport across the section is zero, which has a negligible impact on our calculation.

\section{d. ECCO state estimate}

All budget terms in Eq. (1) are quantified in the ECCO state estimate for both subregions of the subtropical gyre. The ECCO version 4 release 2 state estimate has global $1^{\circ}$ grid spacing with tropical and high-latitude mesh refinement (Wunsch and Heimbach 2013a; Forget et al. 2015; ECCO Consortium 2017a,b). The state estimate is obtained by solving a least squares fit to most available ocean data using Lagrange multipliers. The result is a free-running version of the MIT general circulation model (MITgcm; Adcroft et al. 2004) whose initial conditions, boundary conditions, and internal parameters have been adjusted to reproduce the observed ocean state within error estimates (Wunsch and Heimbach 2007, 2013a; Stammer et al. 2016). The ECCO state estimate is suitable for estimating budgets because it satisfies conservation laws for enthalpy, energy, salt, volume, and momentum, in contrast to most reanalysis products. Despite its relatively coarse resolution, the ECCO version 4 model has also been shown to reproduce the essential features of the North Atlantic circulation, in particular the transports of the Gulf Stream and the net overturning circulation (Wunsch and Heimbach 2013b).

In the ECCO state estimate the full barotropic vorticity budget can be calculated using online momentum diagnostics. Sonnewald et al. (2019) describe the time-mean global budget closure in ECCO; in this study we analyze monthly averages from 1992 to 2012 . We vertically integrate the monthly average momentum diagnostics offline, take their curl, and integrate over the region of interest to obtain the vorticity budget terms. We use $64.5^{\circ} \mathrm{W}$ as the boundary between the eastern and western subregions in ECCO so as to avoid the control volume boundary intersecting islands in the Caribbean (Figs. 1 and 2).

Because of numerical errors associated with the direct calculation of bottom pressure torques in areas with steep topography, the bottom pressure torque term is inferred as a residual from all other budget terms. A similar numerical error was documented by Hughes (1995), who found that the discretization of the advection of potential energy is problematic when the topography changes by more than one discrete depth level. This has been improved upon by the implementation of partially filled cells in the MITgcm, but large jumps in topography remain an issue, even at high resolution. Other issues may arise from the linear freesurface algorithm. These numerical errors affect the bottom pressure torque term as it is directly related to changes in pressure along the bottom and is largest in areas of steep topography. The other terms are not directly affected by these errors. The bottom pressure torque calculated as a residual agrees with the directly calculated bottom pressure torque term away from areas with very steep topography. Because our focus is on the net integral of the bottom pressure torque term, which involves the cancellation of large positive and negative values, we find that calculating the bottom pressure torque term as a residual is preferable to subsequent smoothing or masking of the directly calculated term, as has been done in other studies (e.g., Hughes and de Cuevas 2001; Yeager 2015).

To compare the wind stress forcing term in ECCO with those diagnosed from reanalysis products, we also calculate the ECCO wind stress forcing using the same methods used to calculate the wind stress forcing term from the other products we consider, that is, we interpolate ECCO fields to the SCOW grid, take the curl, and integrate over the same areas. This comparison is detailed in section 3a. In comparing the ECCO planetary vorticity flux to observations, we also calculate the ECCO planetary vorticity flux using the same methods as in our analysis of the A22 data, as detailed in section $3 \mathrm{~b}$.

\section{Results}

\section{a. Wind stress forcing}

The westerlies and trade winds create a dominant anticyclonic pattern of wind stress curl over the subtropics, which corresponds to a source of negative vorticity for the 
TABLE 1. Summary of barotropic vorticity budget terms: time-mean wind stress forcing from products detailed in the text, all time-mean budget terms from the ECCO state estimate, and planetary vorticity flux calculated from A22 hydrographic data. Budget terms are calculated over the western and eastern regions depicted in Figs. 1 and 2. The reported spread on all wind stress forcing and ECCO terms are $95 \%$ confidence intervals on the mean of the time series calculated using the bootstrapping technique with 10000 samplings. The asterisk (*) indicates that planetary vorticity flux estimates from A22 hydrographic data (Fig. 4) are for snapshots in time and their uncertainty is discussed in section $3 \mathrm{~b}$. The ECCO wind stress forcing terms in parentheses are calculated using the same method, mask, and time period as the reanalysis products (Fig. 2). The western region ECCO planetary vorticity flux value in parentheses is calculated directly from ECCO velocities (Fig. 5). All other ECCO budget terms are calculated using momentum budget diagnostics as described in section 2 .

\begin{tabular}{llcr}
\hline \hline Vorticity budget term & Data product & Western region $\left(\times 10^{2} \mathrm{~m}^{3} \mathrm{~s}^{-2}\right)$ & ${\text { Eastern region }\left(\times 10^{2} \mathrm{~m}^{3} \mathrm{~s}^{-2}\right)}$ \\
\hline Wind stress forcing & SCOW & $-1.4 \pm 0.4$ & $-6.1 \pm 1.1$ \\
& NASA MERRA & $-2.4 \pm 0.3$ & $-6.9 \pm 0.6$ \\
& ERA-Interim & $-1.8 \pm 0.3$ & $-7.4 \pm 0.6$ \\
& ECCO & $-0.2 \pm 0.1$ & $-5.5 \pm 0.4$ \\
Planetary vorticity flux & A22 2003 & $(-1.5 \pm 0.2)$ & $-6.3 \pm 0.6)$ \\
& A22 2012 & $-9.5^{*}$ & $-9.0^{*}$ \\
& ECCO & $-10.6 \pm 0.3$ & $11.5 \pm 0.3$ \\
Bottom pressure torque & ECCO & $(-11.0 \pm 0.3)$ & $-5.4 \pm 0.2$ \\
Dissipation & ECCO & $10.8 \pm 0.4$ & $-0.60 \pm 0.04$ \\
Nonlinear & ECCO & $-0.05 \pm 0.01$ & $-0.043 \pm 0.003$ \\
\hline
\end{tabular}

subtropical North Atlantic (Fig. 2). The time averaged wind stress forcing term estimated from all data products is robustly negative over both the eastern and western regions of the subtropical gyre, with the forcing over the eastern region consistently a factor of 3 or 4 larger than over the western region, primarily due to large contributions along the zonal boundaries of the eastern region. The mean wind stress forcing over the western region ranges from -1.4 to $-2.4 \times 10^{2} \mathrm{~m}^{3} \mathrm{~s}^{-2}$ in the SCOW, MERRA, and ERA reanalysis products and from -6.1 to $-7.4 \times$ $10^{2} \mathrm{~m}^{3} \mathrm{~s}^{-2}$ over the eastern region (Table 1 ).

The wind stress forcing in the ECCO state estimate compares well when it is calculated using the same methods as used for the other products (western region: $-1.5 \times 10^{2} \mathrm{~m}^{3} \mathrm{~s}^{-2}$; eastern region: $\left.-6.3 \times 10^{2} \mathrm{~m}^{3} \mathrm{~s}^{-2}\right)$. However, the wind stress forcing calculated on the ECCO grid is generally smaller in magnitude: (western region: $-0.2 \times 10^{2} \mathrm{~m}^{3} \mathrm{~s}^{-2}$; eastern region: $-5.5 \times$ $10^{2} \mathrm{~m}^{3} \mathrm{~s}^{-2}$ ), over the western and eastern regions, respectively, regardless of whether the average is taken over the full 20 years (1992-2012) or just the QuikSCAT era (1999-2009). All time averaged wind stress forcing values are quoted with $95 \%$ confidence intervals in Table 1, evaluated using a bootstrap method with 10000 resampled time series (Efron and Gong 1983). The differences between the ECCO wind stress forcing calculated on the SCOW grid versus the ECCO grid, are primarily due to the Caribbean islands. Because of its $1^{\circ}$ grid spacing, the Caribbean islands are blocky in the ECCO model, and some islands are not resolved (Fig. 2d). The differences are due to the additional wind stress forcing present in ECCO where islands block this forcing in reality.

The MERRA and ERA wind stress forcing terms exhibit similar variability and are highly correlated $(r=$ 0.99; Fig. 3). However, there are small offsets between their mean values: the MERRA wind stress forcing term has greater magnitude than ERA's over the western region, whereas the ERA wind stress forcing term has greater magnitude in the east. The ECCO wind stress forcing calculated using the same method is also correlated with the MERRA and ERA wind stress forcing with $r=0.9$ (Fig. 3); its mean is weaker than MERRA's and ERA's in both regions.

A seasonal cycle is evident in all wind stress products with the most negative wind stress occurring early in the calendar year (Fig. 3), corresponding with the winter storm season in the northern reaches of our domain (Rivière and Orlanski 2007), as well as seasonal strengthening of the trade winds (Wyrtki 1974). The wind stress forcing is negative throughout the year over the eastern region, but over the western region there were periods when the wind stress forcing was positive. Though it is based on the same 10 years that are shown for the MERRA and ERA products, the SCOW climatology was designed to represent an unremarkable year having no large storm events. It is therefore consistent with our expectations that its mean wind stress forcing values over the eastern and western regions are smaller in magnitude than the other products and that the SCOW wind stress forcing climatology has a smaller range (Fig. 3). 

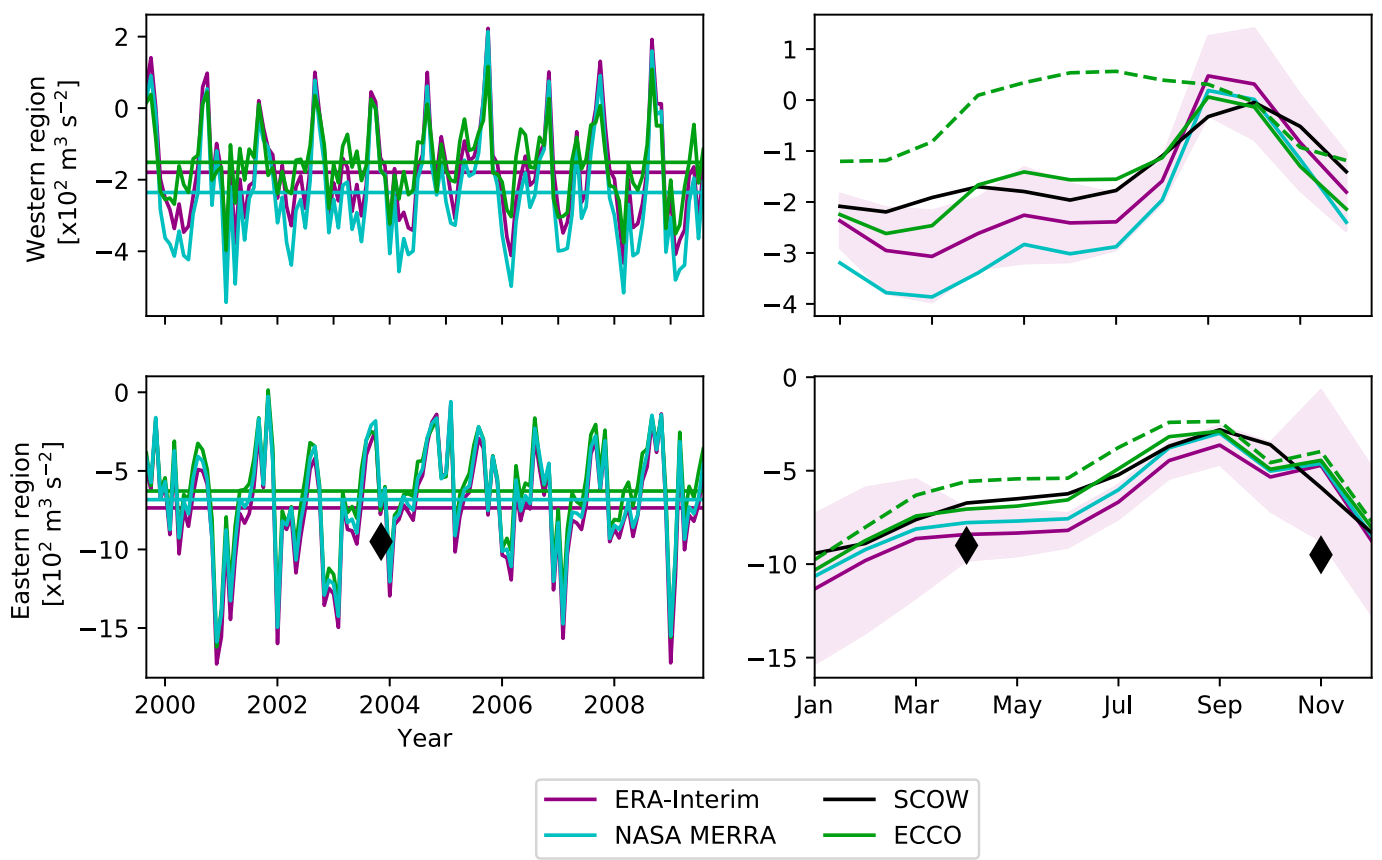

FIG. 3. Time series of wind stress forcing budget term for (left) ERA-Interim, NASA MERRA, and ECCO during the QuikSCAT era (September 1999-2009) and (right) their seasonal climatologies, shown with the SCOW climatology. Solid green lines show ECCO wind stress forcing calculated using the same grid and regions as for the other products, while the green dashed lines (right panels only) show the seasonal ECCO wind stress forcing for regions defined using the ECCO grid. Wind stress forcing time series over the (top) western and (bottom) eastern region, as shown in Fig. 2. The light purple shading on the right denotes one standard deviation about the mean for the ERA-Interim wind stress forcing estimates. Note that each panel has a different $y$ axis range. The horizontal lines in the left panels highlight the mean wind stress forcing values, which are reported in Table 1 . The black diamonds in the bottom panels show the magnitude of the planetary vorticity flux estimated from the November 2003 and April 2012 A22 hydrographic data.

The wind stress in the ECCO state estimate is based on QuikSCAT data when available and climatological QuikSCAT data otherwise, but is adjusted to fit ocean observations within uncertainties under ECCO's dynamically consistent framework (Wunsch and Heimbach 2013a; Forget et al. 2015). The seasonal evolution of the wind stress forcing in the ECCO state estimate during the QuikSCAT era is comparable to that in the other data products when it is calculated over exactly the same regions (solid green line, Fig. 3). However, the seasonal evolution of the ECCO wind stress forcing over the western region deviates significantly when it is calculated on the ECCO grid, again, due to its treatment of wind over the Caribbean islands (dotted green line, Fig. 3).

We further tested the sensitivity of the wind stress forcing values to the calculation method in two ways. First, we took the contour integral of the wind stress projected onto the boundary, which is equivalent to the area integral of the curl through Stokes' theorem. The results were only weakly sensitive to this alternate integration method, due to numerical differences: the time-mean wind stress forcing varied by less than 0.2 and $0.4 \times 10^{2} \mathrm{~m}^{3} \mathrm{~s}^{-2}$ for the western and eastern regions, respectively, which is within the reported confidence intervals on the mean in all reanalysis products (see Table 1). Additionally, we took the curl of MERRA and ERA on their native grids before interpolating onto the SCOW grid and integrating. The ERA mean wind stress forcing in the western region was very sensitive to this change, and increased by $50 \%$. This is because taking the curl on the coarser ERA grid resulted in large wind stress curl values between the land and the ocean that are projected onto the ocean by the interpolation to the SCOW grid. The remaining estimates stayed within the confidence intervals of their mean values.

In sum, the wind stress forcing is a source of negative vorticity over the subtropical gyre. The majority of this negative forcing enters over the larger eastern region we define, and its seasonal and interannual variability is similar in all products. The wind stress forcing over the western region is smaller and more sensitive to the calculation method because of its complicated boundaries, which include the Caribbean islands. These wind stress 
forcing estimates set the stage for comparison with the planetary vorticity flux.

\section{b. Planetary vorticity flux}

The planetary vorticity flux is given by the integral of the product of the depth-integrated velocity normal to the bounding contour $\mathbf{U} \cdot d \mathbf{n}$ multiplied by the planetary vorticity $f$ on the contour. The primary feature in the depth-integrated normal velocity in both realizations of the A22 section is the Gulf Stream at the northern end of the track, which is $\approx 200 \mathrm{~km}$ wide on the continental rise (Fig. 4b). Its maximum depth-averaged velocities are about $0.4 \mathrm{~m} \mathrm{~s}^{-1}$. As the Gulf Stream dominates the scale in Fig. 4b, the significance of the remaining flow features can best be appreciated by considering the negative cumulative sum of the volume transport across the section (Fig. 4c). The barotropic eastward Gulf Stream flow is compensated in part by recirculations directly to its north and south; the northern recirculation includes the Deep Western Boundary Current (Fig. 1). In the 2012 occupation, a strong, narrow recirculation just south of the Gulf Stream was resolved by one pair of stations, while in 2003 only the broad $O(200) \mathrm{km}$ southern recirculation is apparent. There is the westward flow of the Caribbean Current at the very south of the track as well as that of the Antilles Current just north of Puerto Rico (Figs. 1 and 4). The DWBC flows eastward alongside and north of the Antilles Current. Note that the difference in position of the Caribbean Current in the 2003 and 2012 occupations is exaggerated by the horizontal coordinate: the distance from the northernmost station (Fig. 4).

As there is no net volume transport across the section $\left(\int \mathbf{U} \cdot d \mathbf{n}=0\right.$, Fig. $\left.4 \mathrm{c}\right)$, the planetary vorticity flux arises from differences in $f$ between the flows into and out of the western region; the net result is consequently the difference between large numbers (Fig. 4d). To minimize the volume balance component in the cumulative sum of the planetary vorticity flux, we subtract the section mean planetary vorticity $\bar{f}$ from $f$, which does not affect the net planetary vorticity flux (end point of the curves in Fig. 4d). This minimizes the contributions from the flows about the midpoint of the section. Viewed in this manner, it is evident that the planetary vorticity flux is set primarily by the net eastward transport of the Gulf Stream system in the north of the domain.

The estimated net planetary vorticity flux is -9.5 and $-9.0 \times 10^{2} \mathrm{~m}^{3} \mathrm{~s}^{-2}$ for the 2003 and 2012 occupations of A22, respectively (Table 1). To illustrate the sensitivity of this calculation to small changes in velocity, we did a Monte Carlo simulation with 10000 realizations. A pseudorandom velocity error was added to the depthaveraged velocity at each station pair having a Gaussian
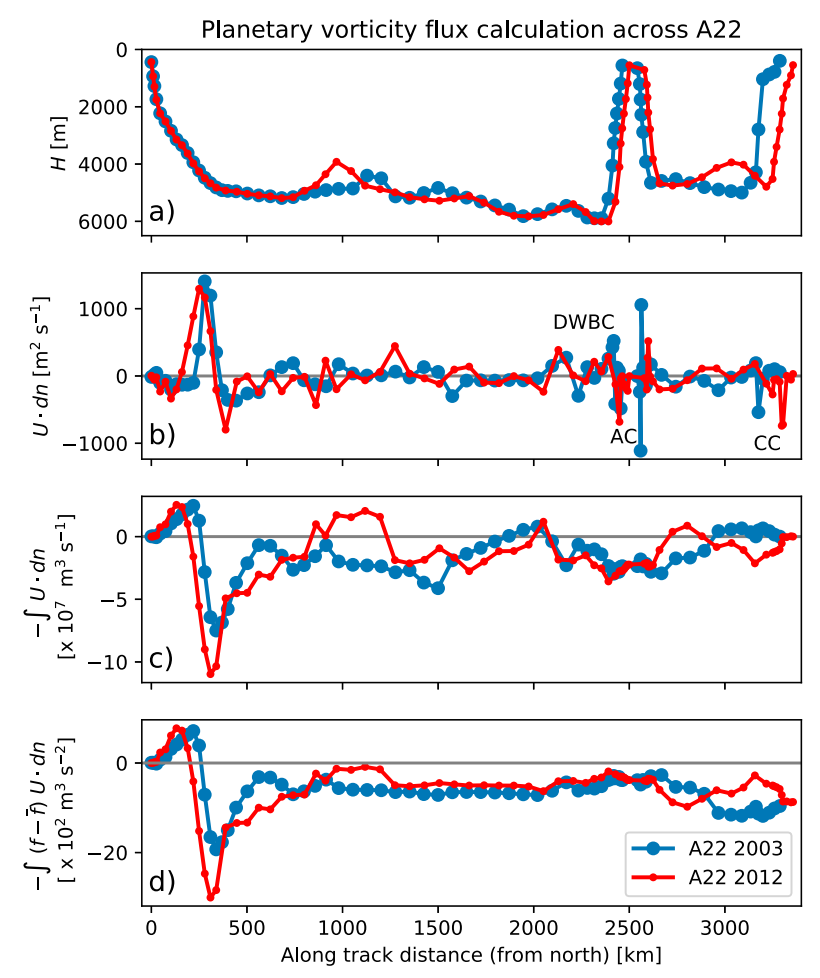

FIG. 4. Breakdown of the planetary vorticity flux calculation across the A22 section. All fields are presented as a function of distance from the northernmost point. (a) Full depth of the water column $H$ along the A22 cruise track. (b) Depth-integrated acrosstrack velocity $\mathbf{U} \cdot d \mathbf{n}$ diagnosed from A22 observations (CasanovaMasjoan et al. 2018). Currents at the south of the domain are labeled; DWBC: Deep Western Boundary Current; AC: Antilles Current; and CC: Caribbean Current. (c) The cumulative sum of the depth-integrated across-track velocity, showing volume balance across the A22 section. (d) The cumulative sum of the product of $\mathbf{U} \cdot d \mathbf{n}$, and the planetary vorticity anomaly $(f-\bar{f})$, where $\bar{f}$ is the average of $f$ along the cruise track. The end point of these curves correspond to the planetary vorticity flux across the line; these are quoted in Table 1. Note that this sum is equivalent to the net planetary vorticity flux $\int f U \cdot d n$, as $\int \bar{f} U \cdot d n=0$.

distribution centered at zero with a half-width of $1 \mathrm{~cm} \mathrm{~s}^{-1}$. We volume balanced this additional velocity by applying a uniform velocity adjustment to each Monte Carlo realization and then calculated the planetary vorticity flux. The distribution of all 10000 realizations gives $95 \%$ confidence intervals of \pm 6.8 and $6.7 \times$ $10^{2} \mathrm{~m}^{3} \mathrm{~s}^{-2}$ on the 2003 and 2012 estimates respectively. This uncertainty estimate is over $70 \%$ of our planetary vorticity flux estimates, highlighting the sensitivity of this calculation to the velocity distribution along the section. In addition to being sensitive to random error (processed LADCP velocity data have an rms error of $<3 \mathrm{~cm} \mathrm{~s}^{-1}$; Thurnherr 2010), LADCP data are also prone to slowly varying referencing biases which could introduce a linear offset our results. Such biases should 
be minimized by the mass-balance inversion of Casanova-Masjoan et al. (2018), but small artifacts may remain.

We calculate the planetary vorticity flux in the ECCO state estimate across a boundary similar to the A22 cruise track: $64.5^{\circ} \mathrm{W}$ and $41^{\circ} \mathrm{N}$ (Fig. 1). This calculation can be broken down in a similar manner to the calculation from the A22 data (Fig. 5). The Gulf Stream is much wider and slower in the ECCO state estimate than in the A22 data due to its $1^{\circ}$ grid spacing: note the order of magnitude difference between the scales in Figs. $4 \mathrm{~b}$ and $5 \mathrm{~b}$. The ECCO state estimate also does not have significant northern and southern recirculation gyres at the flanks of the Gulf Stream. However, the net transport of the Gulf Stream in ECCO is similar in magnitude to that of the combined Gulf Stream and its recirculations in the A22 data (Fig. 5c). The depthintegrated velocities of the outflowing Deep Western Boundary Current and inflowing Caribbean Current in the south of the domain are much more comparable in magnitude to the Gulf Stream in ECCO than they are in reality. As with the Gulf Stream system, though, their net transports in ECCO are similar to the A22 estimates. At the same time, the Antilles/Caribbean Current makes a more significant contribution to the net planetary vorticity flux in ECCO than it does in the A22 data (Fig. 5d).

We estimate the planetary vorticity flux in ECCO in two ways. First, as for all other ECCO terms, we integrate the curl of the depth-integrated momentum diagnostic. Using this method, the time mean planetary vorticity flux over the western region in the ECCO state estimate is $-10.6 \pm 0.3 \times 10^{2} \mathrm{~m}^{3} \mathrm{~s}^{-2}$. We also estimate the western planetary vorticity flux directly from the ECCO velocities in the manner that we estimate it from the A22 observations, as depicted in Fig. 5, which gives $-11.0 \pm 0.3 \times 10^{2} \mathrm{~m}^{3} \mathrm{~s}^{-2}$. The $95 \%$ confidence intervals of these two mean values overlap, and we show both their time series in Fig. 6a. Our planetary vorticity flux estimates from the $\mathrm{A} 22$ data do fall within the range of values in the ECCO state estimate, but the spread in the ECCO time series further emphasizes that our calculations from observations can only give an order of magnitude estimate for the planetary vorticity flux.

To compare the A22 velocities and the ECCO fields directly, we smoothed the depth-integrated A22 velocities using a second order Butterworth filter with a $600-\mathrm{km}$ cutoff. The resulting fields have representations of the Gulf Stream that resemble that in ECCO, and the widths and strengths of the remaining currents are on the same order (Fig. 5). To calculate a meaningful planetary vorticity flux, we enforced volume balance by applying a constant depth-integrated velocity correction.
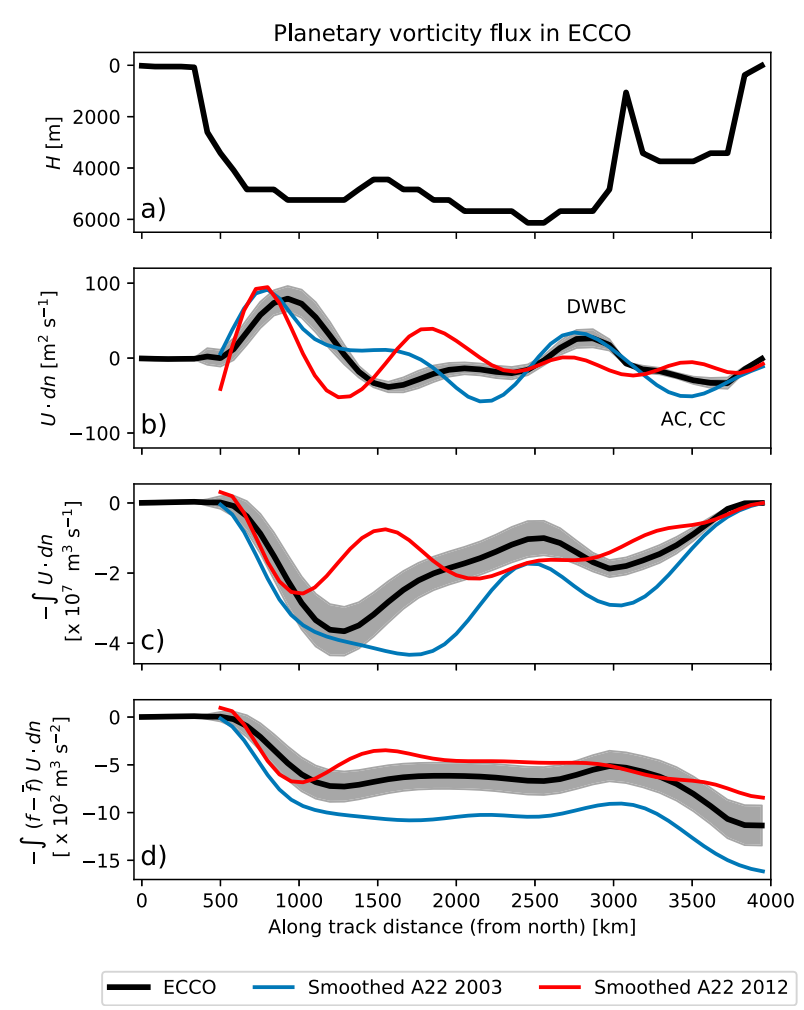

FIG. 5. Planetary vorticity flux breakdown in ECCO, mirroring Fig. 4 for the equivalent ECCO cruise track shown in Fig. 1. The thick black lines are 20-yr means, and the gray envelope shows \pm 1 standard deviation from monthly mean fields. A22 observations smoothed with a 600-km cutoff to resemble ECCO's resolution are overlain in blue and red lines. The end point of the thick black line in (d) is the time-averaged planetary vorticity flux in ECCO quoted in Table 1. As in Fig. 4, currents at the south of the domain are labeled in (b); DWBC: Deep Western Boundary Current; AC: Antilles Current; and CC: Caribbean Current.

The resulting planetary vorticity flux for the smoothed A22 observations were -16 and $-8.4 \times 10^{2} \mathrm{~m}^{3} \mathrm{~s}^{-2}$ for 2003 and 2012, respectively. This wide range further highlights the sensitivity of the planetary vorticity flux to the velocity distribution.

The planetary vorticity flux in the ECCO state estimate at the time of the November 2003 A22 section occupations is $-11.2 \times 10^{2} \mathrm{~m}^{3} \mathrm{~s}^{-2}$, compared to the $-9.5 \times 10^{2} \mathrm{~m}^{3} \mathrm{~s}^{-2}$ estimate from the $2003 \mathrm{~A} 22 \mathrm{ob}-$ servations (Fig. 6a). The April 2012 occupation is outside of the ECCO version 4 release 2 time span, but lies within the climatological range (Fig. 7a). In sum, the planetary vorticity flux estimated from the hydrographic data are on the same order as instantaneous (Fig. 6), climatological (Fig. 7), and time average (Table 1) estimates of planetary vorticity flux from ECCO. The planetary vorticity flux in ECCO is generally larger because of outsized contributions from the Antilles/Caribbean Currents. 

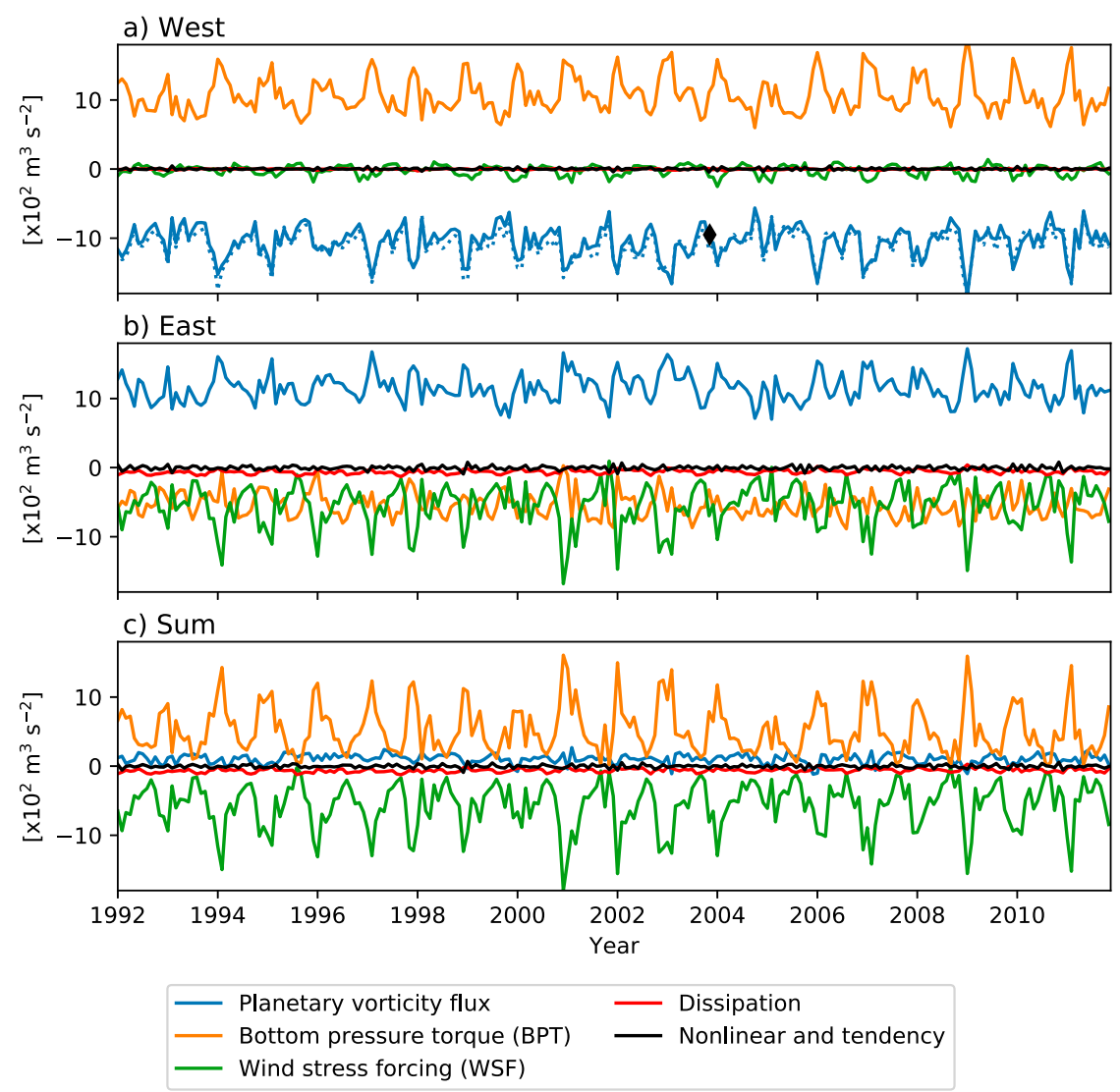

FIG. 6. Full ECCO state estimate vorticity budget terms for (a) the western subtropical gyre region, (b) the eastern subtropical gyre region, and (c) the full subtropical gyre (sum of western and eastern regions). All terms are calculated by integrating the curl of the depthintegrated ECCO momentum equation diagnostics. Additionally, the planetary vorticity flux in the western region calculated directly from the ECCO velocity fields (Fig. 5) is displayed by the dotted line in (a). Regional boundaries are shown in Fig. 2d. The time mean of all terms are quoted in Table 1 . The black diamond in (a) shows the magnitude of the planetary vorticity flux estimated from the November 2003 A22 hydrographic data.

The A22 planetary vorticity flux estimates for the western subtropical gyre are several times larger than all wind stress forcing estimates over the western subtropical gyre (Fig. 3, Table 1), suggesting that the barotropic vorticity budget for the western subtropical gyre must be closed by a term that is not calculated from observations, such as friction (Stommel 1948; Munk 1950) or bottom pressure torques (Hughes 2000). We discuss the budget closure for the western subtropical gyre in the ECCO state estimate in section 3c.

The estimates of planetary vorticity flux for the western subtropical gyre from the A22 hydrographic data can be thought of as estimates for the eastern subtropical gyre assuming that the net planetary vorticity flux through the northern and southern boundaries of the eastern region is a small fraction of the total eastern region planetary vorticity flux, which we do find to be the case in ECCO. In ECCO, the mean planetary vorticity flux out of the western region is $10.6 \times$ $10^{2} \mathrm{~m}^{3} \mathrm{~s}^{-2}$, and the mean into the eastern region is $11.5 \times$ $10^{2} \mathrm{~m}^{3} \mathrm{~s}^{-2}$ (Table 1), so the contribution from the northern and southern boundaries of the eastern region (i.e., their difference) is less than $10 \%$ of the total. Assuming this holds in the observations, then, we can test barotropic Sverdrup balance over the eastern subtropical gyre by comparing the planetary vorticity flux estimate from the A22 data and the wind stress forcing over the eastern subtropical gyre estimated from the SCOW, ERA, and MERRA products.

The November 2003 wind stress forcing estimates over the eastern subtropical gyre are -7.5 and $-8.2 \times$ $10^{2} \mathrm{~m}^{3} \mathrm{~s}^{-2}$ from MERRA and ERA, respectively, compared to the 2003 A22 planetary vorticity flux estimate of $-9.5 \times 10^{2} \mathrm{~m}^{3} \mathrm{~s}^{-2}$ (Fig. 3). The April 2012 occupation falls outside of the QuikSCAT time period we consider, but the April climatological wind stress forcing over the 
a) West

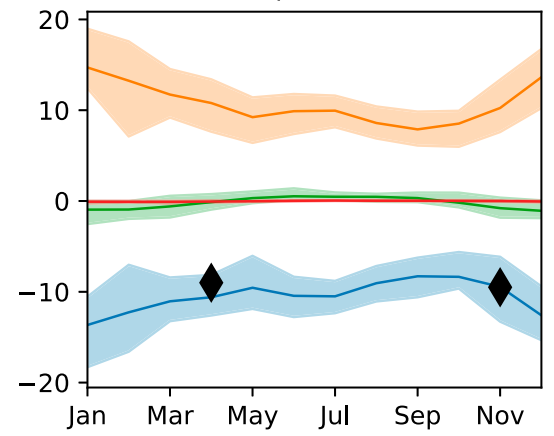

b) East

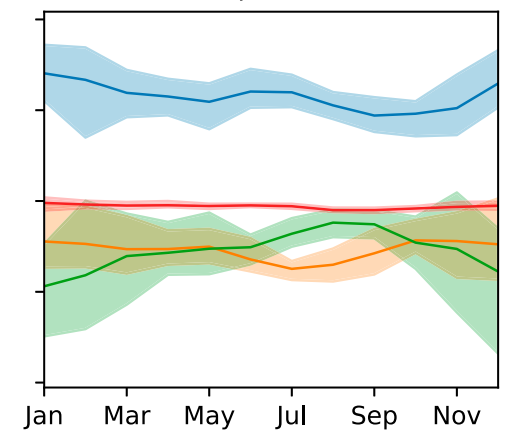

c) Sum

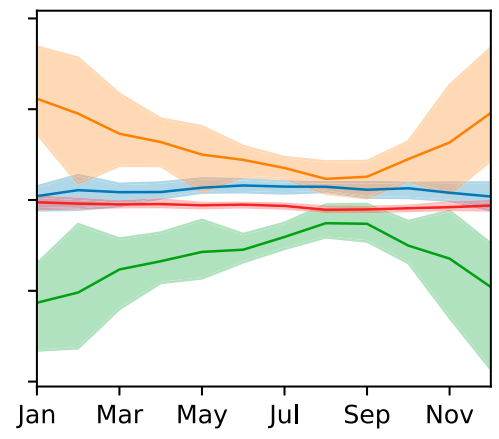

Planetary vorticity flux

Bottom pressure torques

Wind stress forcing Dissipation

FIG. 7. Seasonal climatology of the ECCO vorticity budget over (a) the western subtropical gyre region, (b) eastern subtropical gyre region, and (c) the full subtropical gyre. Shading shows the range between the minimum and maximum budget term values in each month. The black diamonds in (a) show the magnitude of the planetary vorticity flux estimated from the April 2012 and November 2003 A22 hydrographic data.

eastern subtropical gyre: $-8.8,-8.0$, and $-6.8 \times$ $10^{2} \mathrm{~m}^{3} \mathrm{~s}^{-2}$ from ERA, MERRA, and SCOW, respectively, are closer to the 2012 A22 estimate $(-9.0 \times$ $\left.10^{2} \mathrm{~m}^{3} \mathrm{~s}^{-2}\right)$ than the time-mean wind stress forcing over the eastern region, which is smaller in magnitude than the April and November climatological values (Fig. 3).

In general, the planetary vorticity flux through the A22 section is similar in size to the wind stress forcing calculated from the SCOW, ERA and MERRA products over the eastern subtropical gyre (Fig. 3, Table 1), pointing to an approximate barotropic Sverdrup balance over the eastern subtropical gyre. The wind stress forcing term is consistently smaller in magnitude in ECCO than in the other data products we consider, and the planetary vorticity flux in ECCO is larger than our estimates from the A22 hydrographic data. Hence, in the ECCO state estimate the wind stress forcing over the eastern region is only about half of the planetary vorticity flux, suggesting a different balance, which is detailed in the next section.

\section{c. ECCO budget closure}

We calculate the full, time-varying budget of barotropic vorticity in the ECCO state estimate from monthly average fields from 1992 to 2012 (Fig. 6), building on Sonnewald et al. (2019), who present the 20 year mean budget. Sonnewald et al. (2019) identify dynamical regimes in ECCO using unsupervised learning and find that most of the subtropical gyre is "quasi-Sverdrupian," with a primary balance between wind stress forcing and planetary vorticity flux. Nonlinear terms contribute to the local balance at the western boundary, and bottom pressure torques are significant at all boundaries of the dynamical subtropical gyre identified by Sonnewald et al. (2019). Here, instead of identifying regions based on their dynamics, we consider the balances within specified geographical regions, motivated by our comparisons with observations.

In the western region the primary time-mean balance in ECCO is between the planetary vorticity flux $\left(-10.6 \times 10^{2} \mathrm{~m}^{3} \mathrm{~s}^{-2}\right)$ and bottom pressure torque $\left(10.8 \times 10^{2} \mathrm{~m}^{3} \mathrm{~s}^{-2}\right)$. The correlation coefficient between ECCO's monthly resolution 20-yr time series is highest at zero lag $(r=-0.9)$, suggesting that the balance holds on monthly time scales. The balance between planetary vorticity flux and bottom pressure torques in the barotropic vorticity equation is analogous to geostrophic balance in the momentum equation. So, the fact that this balance holds on monthly time scales implies (unsurprisingly) that geostrophic adjustment of the depth-integrated flow occurs within a month. This balance stands in contrast to the early theories of Stommel (1948) and Munk (1950), who suggested that the northward flow of the Gulf Stream was enabled by friction. Recall that the Stommel and Munk theories were made for rectangular oceans with flat bottoms. Once a continental slope is included, the depth-integrated flow can conserve potential vorticity as it moves poleward by moving into deeper water. The movement of water across topographic contours is associated with bottom pressure torques, which quantify this form of crossing $f$ contours in the barotropic vorticity framework. It is important to note, however, that this balance does not explain how flow along $f$ contours crosses into shallower water at the western boundary before heading poleward.

In the eastern region, the time-mean planetary vorticity flux $\left(-11.5 \times 10^{2} \mathrm{~m}^{3} \mathrm{~s}^{-2}\right)$ is balanced by the sum of 
the wind stress forcing $\left(5.5 \times 10^{2} \mathrm{~m}^{3} \mathrm{~s}^{-2}\right)$ and bottom pressure torque terms $\left(-5.4 \times 10^{2} \mathrm{~m}^{3} \mathrm{~s}^{-2}\right.$; Table 1$)$. Though they contribute equally in the mean, the wind stress forcing has a larger range and the bottom pressure torque compensates for extreme values in the wind stress forcing (Fig. 6b). The planetary vorticity flux term exhibits much higher correlation with the wind stress forcing term at zero lag $(r=-0.8)$, than with the bottom pressure torque term $(r=0.1)$. The terms are not better correlated at any other lag. As previously discussed, bottom pressure torques do not force flow in the same way that wind stress forcing does, so the covariability of the wind stress forcing and planetary vorticity flux suggests that the gyre is spun up by the wind stress forcing on monthly time scales in ECCO.

Summing the terms over the two regions yields a diagnosis for the entire subtropical gyre, which is a balance between the wind stress forcing and bottom pressure torques (Fig. 6c). As can be deduced from the separate balances over the eastern and western regions, the wind stress forcing dominates in the eastern portion of the gyre, while bottom pressure torques dominate on the western side. We can break this balance down further by considering the zonal distribution of the dominant terms and their relationship to the planetary vorticity weighted depth-integrated flow in ECCO (fU, Fig. 8). The largest divergences of $f \mathbf{U}$, which correspond to planetary vorticity flux, are between $82^{\circ}$ and $75^{\circ} \mathrm{W}$, where the Florida Current/Gulf Stream flows northward (to larger $f$ ) from Florida Straits to Cape Hatteras. The contributions to the planetary vorticity flux decrease as the Gulf Stream beyond Cape Hatteras turns to become more zonal.

The wind stress forcing accumulates consistently over the center of the subtropical gyre, from $60^{\circ}$ to $20^{\circ} \mathrm{W}$ (Fig. 8). This input of negative vorticity forces a broad southward flow: the planetary vorticity flux changes in concert with the wind stress forcing between these longitudes. There are also southward flows in the eastern region which are supported by bottom pressure torques, most notably in the Deep Western Boundary Current along the eastern flanks of the Caribbean islands and on the eastern boundary of the mid-Atlantic ridge. The mean vorticity balance of the subtropical gyre in ECCO can be summarized as a balance between wind stress forcing that enables southward flow in the east and bottom pressure torques that support enough northward flow in the west to compensate it, as well as additional recirculation in the eastern subtropical gyre.

To better understand the seasonal differences in the vorticity balance, we consider the difference between the vorticity balance in July and January, the two extremes of the seasonal cycle. The net wind stress forcing is largest in January (Fig. 7). In response, depthintegrated anticyclonic gyres speed up on either side of the mid-Atlantic (Fig. 9). These flows are enabled by changes in bottom pressure torque along continental slopes and the mid-Atlantic ridge (Figs. 8 and 9). Hence, the gyre is spun up by the wind on seasonal time scales and supported by bottom pressure torques on sloping topography.

In sum, the primary balance of barotropic vorticity over the subtropical gyre in ECCO is between wind stress forcing and bottom pressure torques. Wind stress forcing drives southward flow in the eastern subtropical gyre, while bottom pressure torques enable the northward return flow in the west. Additionally, some southward flow in the eastern subtropical gyre is enabled by bottom pressure torques. This balance holds on monthly time scales, and our analysis indicates that wind stress forcing in the ECCO state estimate spins up gyre motions on time scales shorter than one month.

\section{Conclusions}

\section{a. Discussion}

The goals of this study were 1) to ground truth the barotropic vorticity budget of the subtropical North Atlantic with observations and 2) to examine its variability on subannual time scales. We found reasonable agreement between the budget terms diagnosed from observations and the ECCO state estimate, but our comparison suggests that bottom pressure torques may play a more significant role in ECCO than they do in reality. The large-scale balance between wind stress forcing and bottom pressure torques in ECCO holds on monthly time scales, as do the balances in the eastern and western subregions involving planetary vorticity fluxes, suggesting fast barotropic adjustment time scales. In the following, we place our results in the context of other studies, and discuss the limitations and implications of our results.

Our planetary vorticity flux estimates from A22 hydrographic data compare better with the 20-yr planetary vorticity flux mean value from ECCO than with ECCO monthly and climatological values (Figs. 6 and 7, Table 1), however we note that our estimate from the A22 hydrographic data has large uncertainty, which renders such differences statistically insignificant. The planetary vorticity flux in ECCO generally has larger magnitude than our estimates from A22 due to outsized contributions from the Caribbean inflow in the south of the domain (Fig. 5).

The wind stress forcing in ECCO is weaker than in all other wind stress data products we consider: NASA 

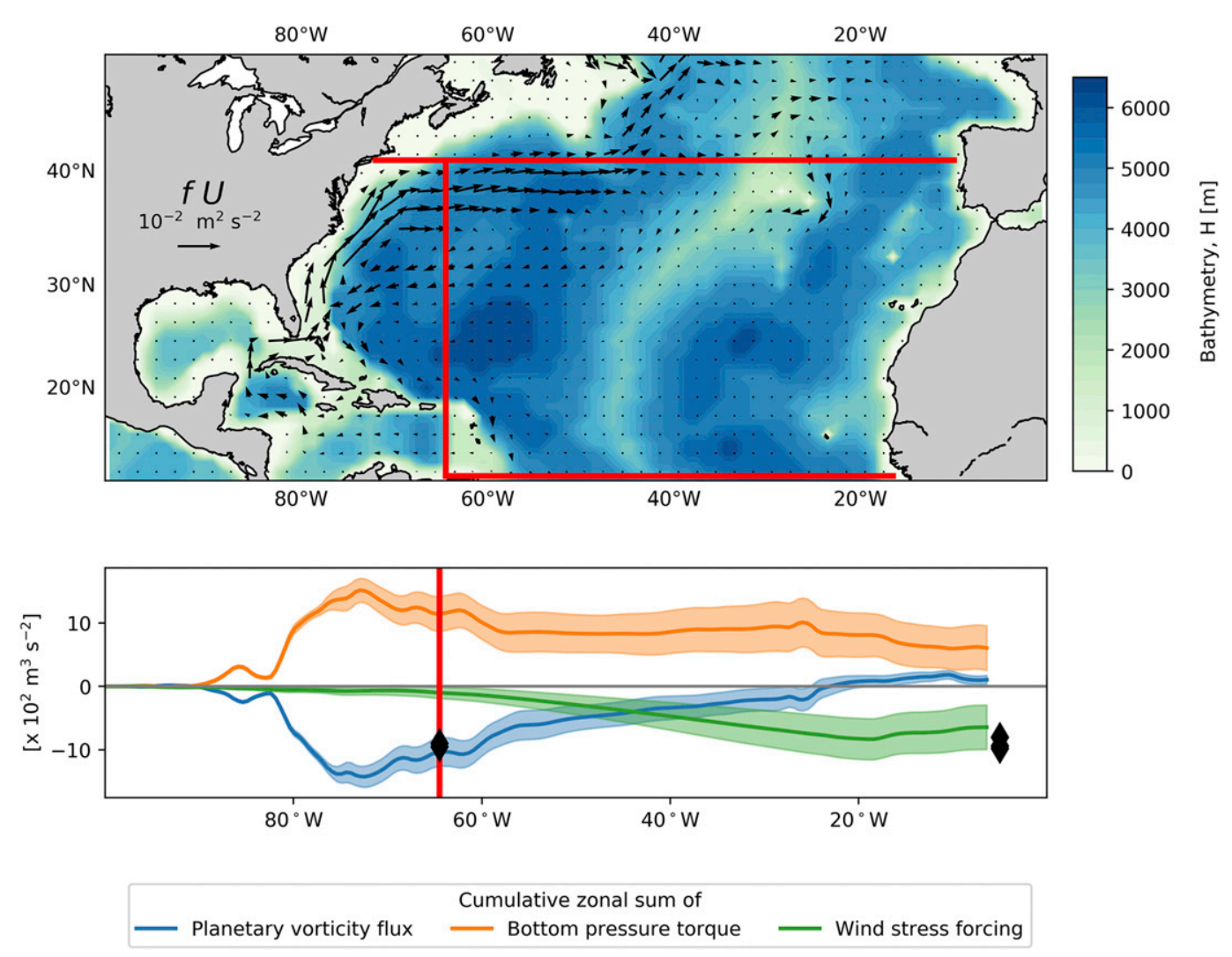

FIG. 8. (top) Map showing the relationship between depth-integrated flow weighted by planetary vorticity $f \mathbf{U}$, and bathymetry in ECCO. Black arrows depict $f \mathbf{U}$; only every other gridpoint is plotted for visual clarity. Red lines depict the boundaries of the vorticity budget in ECCO. (bottom) Cumulative zonal sum of the primary ECCO vorticity budget terms starting from the western boundary. The solid line shows the 20 -yr time mean, and shading shows \pm 1 standard deviation in the cumulative sum of each term. The vertical red line at $64.5^{\circ} \mathrm{W}$ highlights the boundary between the western and eastern regions. The black diamonds at $64.5^{\circ} \mathrm{W}$ show the magnitudes of the planetary vorticity flux estimated from the A22 hydrographic data, and the black diamonds at $5^{\circ} \mathrm{W}$ show the timemean wind stress forcing over the entire subtropical gyre estimated from the SCOW, ERA-Interim, and NASA MERRA wind stress products (see Table 1).

MERRA, ERA-Interim, and the SCOW climatology (Fig. 8, Table 1). However, when the wind stress forcing in ECCO is calculated using the same grid as the other products, their agreement improves, particularly over the western region, where the difference stems from the way that ECCO treats the Caribbean islands (Fig. 3, Table 1). Across all products there is a winter peak in wind stress forcing (Fig. 3). The wind stress forcing over the eastern subtropical gyre is several times larger than over the western subtropical gyre in all data products considered.

The differences between budget terms calculated from observations and from the ECCO state estimate are large enough that the inferred vorticity budgets for the eastern subtropical gyre from observations and ECCO differ. The planetary vorticity flux estimated from the A22 hydrographic data compares well with the wind stress forcing over the subtropical gyre from reanalysis products, particularly with ERAInterim. This suggests a barotropic Sverdrup balance over the eastern subtropical gyre. In ECCO, however, the planetary vorticity flux into the eastern subtropical gyre is balanced in equal parts by the wind stress forcing and bottom pressure torques. This suggests that bottom pressure torques may play too large a role in the ECCO model, which is consistent with the findings of Schoonover et al. (2015), who found that coarser resolution models tend to overemphasize the role of bottom pressure torques.

We find that the barotropic gyre adjusts to the wind stress forcing over the eastern subtropical gyre in less than one month, which is significantly faster than the several-year equilibration time for Sverdrup balance suggested by Thomas et al. (2014). There are some significant differences between our study and Thomas et al. (2014): their focus is on pointwise and zonally integrated 

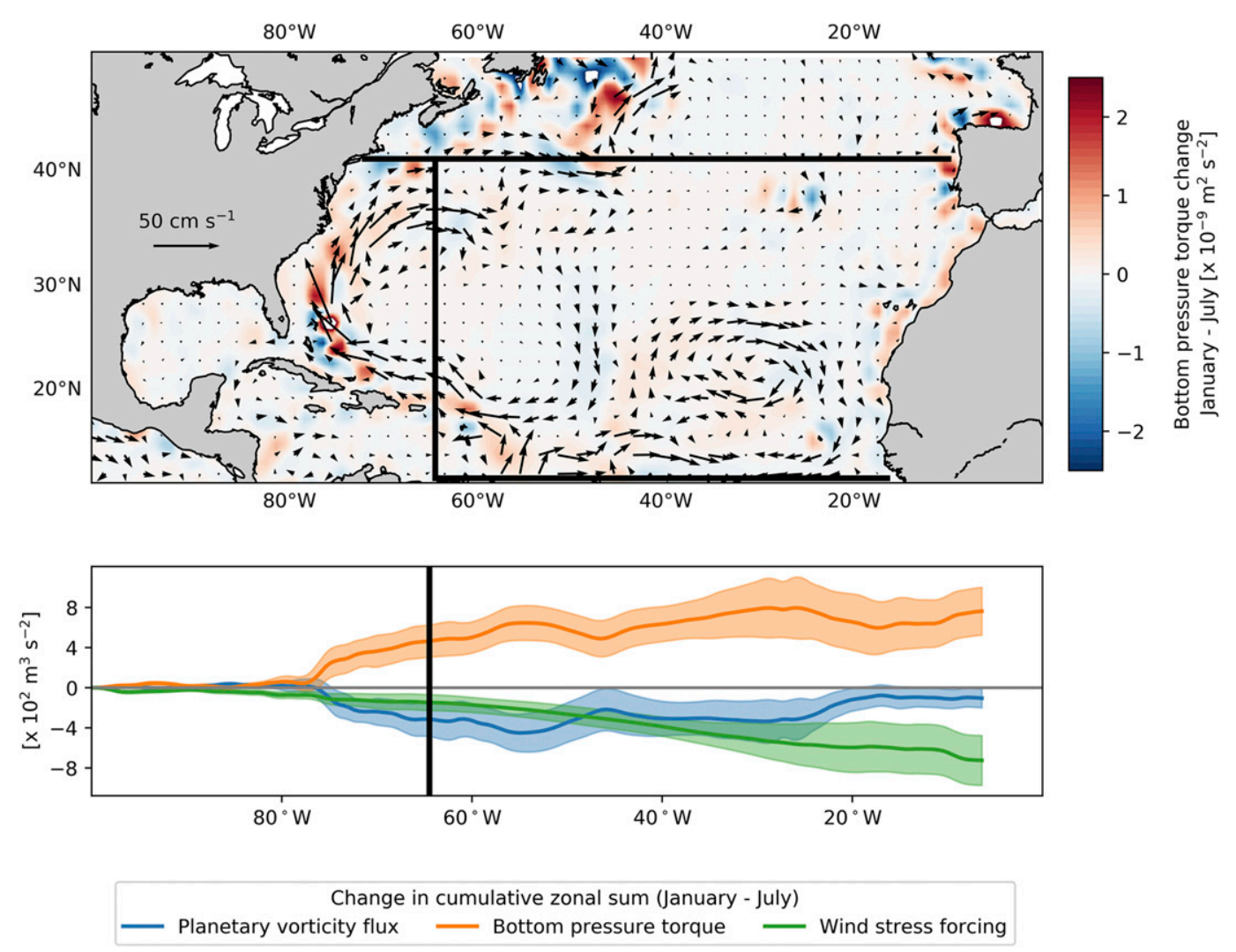

FIG. 9. (top) Map highlighting the mean changes in bottom pressure torque from July to January. Black arrows depict the climatological changes in $\mathbf{U}$ from July to January; only every other gridpoint is plotted for visual clarity. Black lines depict the boundaries of the vorticity budget in ECCO. (bottom) Cumulative sum of the January-July difference in the primary ECCO vorticity budget terms starting from the western boundary. The solid line shows the 20 -yr time mean, and shading shows \pm 1 standard deviation in the cumulative sum of the difference for each term. The vertical black line at $64.5^{\circ} \mathrm{W}$ highlights the boundary between the western and eastern regions.

Sverdrup balance above a level of no motion, while we integrate over the full water column and over large spatial regions. Because of our horizontal integration over large regions, we filter out small-scale contributions to the budget, and by integrating over the full water depth we eliminate mass storage within the subtropical thermocline (Zhao and Johns 2014; Evans et al. 2017). These integrations may account for the differences in adjustment time scale that we find.

The magnitude of our budget terms can be compared with those in Schoonover et al. (2015), who calculate a barotropic vorticity balance for the Gulf Stream in six models with different frameworks and resolutions. Their budget region is defined by transport contours, and roughly corresponds to the western continental slope between the Florida Straits and Cape Hatteras (their Fig. 4). This is a much smaller region than the western region we define in ECCO, but the contributions to our budget are largest between the Florida Straits and Cape Hatteras, so that our budget should be comparable to that of Schoonover et al. (2015). They find a planetary vorticity fluxes ranging from about 3 to $15 \times 10^{2} \mathrm{~m}^{3} \mathrm{~s}^{-2}$, with most models around $5 \times 10^{2} \mathrm{~m}^{3} \mathrm{~s}^{-2}$ (their Fig. 5). Our planetary vorticity flux estimates from A22 and ECCO fall within this range. Though the magnitude of the term varies, all models examined by Schoonover et al. (2015) show a balance between planetary vorticity flux and bottom pressure torques for the Gulf Stream, as we find in ECCO.

Though the same large-scale vorticity balance holds across model platforms and resolutions, the details of local vorticity balances are quite different (Schoonover et al. 2015). The nonlinear term is significant for the local balance at the western boundary of the subtropical gyre in ECCO (Sonnewald et al. 2019), and it is likely larger in higher-resolution models. The nonlinear term is known to be significant in shaping the Gulf Stream's inertial recirculation gyres (Rhines and Young 1982; Hogg et al. 1986; Cessi 1990; Waterman and Jayne 2012; Le Bras et al. 2018), which ECCO lacks at $1^{\circ}$ spatial 
resolution. Different representations of friction can also impact barotropic budget closures significantly (Dewar 1998; Schoonover et al. 2015). Both nonlinearity and friction may impact the monthly equilibration times we find in ECCO.

The gyre-wide fast equilibration times between wind stress forcing and bottom pressure torques we observe are consistent with the fast equilibration to topographic Sverdrup balance by barotropic waves (Anderson and Killworth 1977). This expands on the results of Yeager (2015), who found (in a climate model with similar resolution) that the subtropical gyre can be spun up within a year. Here we show that this adjustment occurs within a month. We note, however, that the ECCO version 4 state estimate does not resolve eddies, which would likely alter the balance on monthly time scales, whether through additional dynamics, or simply because eddies introduce noise. The effect of eddies on the monthly budget closure is an interesting avenue for future research.

We find that barotropic gyres are spun up by the wind seasonally, particularly the Gulf Stream along the continental slope (Fig. 9). This stands in contrast to observational findings that the seasonal variability in Florida Straits Gulf Stream transport is decoupled from Sverdrup balance (Anderson and Corry 1985; Schott et al. 1988) and that the Florida Current transport generally peaks in late spring/early summer (Schott and Zantopp 1985; Beal et al. 2008; Pérez-Hernández et al. 2015). At the same time, the seasonality of the Florida Current has been reported to be nonstationary (Baringer and Larsen 2001; Domingues et al. 2016). Downstream, in the Gulf Stream extension region, the seasonality of Gulf Stream transport is similarly unclear. Oleander ship-of-opportunity ADCP measurements, historical CTDs, and satellite altimetry point to a small late summer peak in baroclinic Gulf Stream transport (Sato and Rossby 1995; Kelly et al. 1999; Rossby et al. 2010). The seasonality of the barotropic transport component of the gyre has not been diagnosed from observations, so we cannot fully ground truth the seasonal spinup of the subtropical gyre in ECCO.

Because the bottom pressure torque does not drive flow in the same way that the wind does, but is a measure of topographic steering, it is not trivial to interpret the meaning of its temporal variability. For example, the correspondence between planetary vorticity flux and bottom pressure torques on monthly time scales in the western subtropical gyre means that the geostrophic flow adjusts on these time scales. The correspondence between variability in the wind stress forcing and planetary vorticity flux points to barotropic gyre spinup by the wind on monthly time scales, yet there is some compensation between the seasonality of the bottom pressure torques and wind stress forcing over the eastern subtropical gyre in the ECCO model (Fig. 7). The planetary vorticity flux term consequently has much less of a range than the wind stress forcing term over the eastern subtropical gyre. This could mean that there are additional recirculations contained within the eastern region, which are forced southward by wind stress forcing and are allowed to return northward by bottom pressure torques, or it could reflect a change in how the flow is distributed in depth. Note that as Holland (1972), Mertz and Wright (1992), and Yeager (2015) point out, the geostrophic bottom velocities associated with bottom pressure torques are the residual between the barotropic and baroclinic contributions to the velocity at the seafloor.

\section{b. Summary}

We find a large-scale vorticity balance in the ECCO state estimate between wind stress forcing in the eastern subtropical gyre and bottom pressure torques in the west. The ECCO budget terms are on the same order as observational planetary vorticity flux and wind stress forcing estimates. Our results are consistent with observational studies centered on Sverdrup balance (e.g., Schmitz et al. 1992; Gray and Riser 2014) and large-scale vorticity balances in a wide range of models (e.g., Schoonover et al. 2015). The emerging view is that the barotropic subtropical gyre is spun up by the wind on monthly time scales and is strongly topographically steered at the western boundary. Important avenues for future inquiry include the role of eddies in this balance and a deeper understanding of how the balance of potential vorticity is maintained along $f / H$ contours.

Acknowledgments. We thank Alonso HernándezGuerra, M. Dolores Pérez-Hernández, and María Casanova-Masjoan for providing the inverse model results from Casanova-Masjoan et al. (2018). The A22 section is part of the WOCE/CLIVAR observing effort, with all data available at http://cchdo.ucsd.edu/. We thank Carl Wunsch, Patrick Heimbach, Chris Hill, and Diana Lees Spiegel for their assistance with the ECCO fields. The state estimates were provided by the ECCO Consortium for Estimating the Circulation and Climate of the Ocean funded by the National Oceanographic Partnership Program (NOPP) and can be downloaded at http://www.ecco-group.org/products.htm. The citable URL for the ECCO version 4 release 2 product is http:// hdl.handle.net/1721.1/102062. We are grateful to Joseph Pedlosky and Glenn Flierl for their comments on an earlier version of this work. IALB and JMT were 
supported financially by U.S. NSF Grants OCE0726720, 1332667, and 1332834. MS was supported by the U.S. NASA Sea Level Change Team (Contract NNX14AJ51G) and through the ECCO Consortium funding via the Jet Propulsion Laboratory. We thank two anonymous reviewers, whose thoughtful comments led to improvements.

\section{REFERENCES}

Adcroft, A., C. Hill, and P. Heimbach, 2004: Overview of the formulation and numerics of the MIT GCM. Seminar on Recent Developments in Numerical Methods for Atmospheric and Ocean Modelling, Reading, United Kingdom, ECMWF, 139_ 150, https://www.ecmwf.int/node/7642.

Anderson, D. L. T., and P. D. Killworth, 1977: Spin-up of a stratified ocean, with topography. Deep-Sea Res., 24, 709-732, https://doi.org/10.1016/0146-6291(77)90495-7.

— , and R. Corry, 1985: Ocean response to low frequency wind forcing with application to the seasonal variation in the Florida Straits-Gulf Stream transport. Prog. Oceanogr., 14, 7-40, https://doi.org/10.1016/0079-6611(85)90003-5.

Baringer, M. O., and J. C. Larsen, 2001: Sixteen years of Florida current transport at 27N. Geophys. Res. Lett., 28, 3179-3182, https://doi.org/10.1029/2001GL013246.

Beal, L. M., J. M. Hummon, E. Williams, O. B. Brown, W. Baringer, and E. J. Kearns, 2008: Five years of Florida Current structure and transport from the Royal Caribbean Cruise Ship Explorer of the Seas. J. Geophys. Res., 113, C06001, https://doi.org/10.1029/2007JC004154.

Casanova-Masjoan, M., T. Joyce, M. Pérez-Hernández, P. VélezBelchí, and A. Hernández-Guerra, 2018: Changes across $66^{\circ} \mathrm{W}$, the Caribbean Sea and the Western boundaries of the North Atlantic Subtropical Gyre. Prog. Oceanogr., 168, 296309, https://doi.org/10.1016/j.pocean.2018.09.013.

Cessi, P., 1990: Recirculation and separation of boundary currents. J. Mar. Res., 48, 1-35, https://doi.org/10.1357/002224090784984597.

Dee, D. P., and Coauthors, 2011: The ERA-Interim reanalysis: Configuration and performance of the data assimilation system. Quart. J. Roy. Meteor. Soc., 137, 553-597, https://doi.org/ 10.1002/qj.828.

Dewar, W. K., 1998: Topography and barotropic transport control by bottom friction. J. Mar. Res., 56, 295-328, https://doi.org/ 10.1357/002224098321822320.

Domingues, R., M. Baringer, and G. Goni, 2016: Remote sources for year-to-year changes in the seasonality of the Florida Current transport. J. Geophys. Res. Oceans, 121, 7547-7559, https://doi.org/10.1002/2016JC012070.

Duchez, A., and Coauthors, 2016: Drivers of exceptionally cold North Atlantic Ocean temperatures and their link to the 2015 European heat wave. Environ. Res. Lett., 11, 074004, https:// doi.org/10.1088/1748-9326/11/7/074004.

ECCO Consortium, 2017a: A twenty-year dynamical oceanic climatology: 1994-2013. Part 1: Active scalar fields: Temperature, salinity, dynamic topography, mixed-layer depth, bottom pressure. ECCO Rep., 54 pp., http://hdl.handle.net/ 1721.1/107613.

, 2017b: A twenty-year dynamical oceanic climatology: 19942013. Part 2: Velocities, property transports, meteorological variables, mixing coefficients. ECCO Rep., 45 pp., http:// hdl.handle.net/1721.1/109847.
ECMWF, 2012: ERA-Interim Project, Monthly Means. Research Data Archive at the National Center for Atmospheric Research, Computational and Information Systems Laboratory, accessed 16 February 2014, https://doi.org/10.5065/D68050NT.

Efron, B., and G. Gong, 1983: A leisurely look at the bootstrap, the jackknife, and cross-validation. Amer. Stat., 37, 36-48, https:// doi.org/10.1080/00031305.1983.10483087.

Evans, D. G., J. Toole, G. Forget, J. D. Zika, A. C. Naveira Garabato, A. J. G. Nurser, and L. Yu, 2017: Recent winddriven variability in Atlantic water mass distribution and meridional overturning circulation. J. Phys. Oceanogr., 47, 633-647, https://doi.org/10.1175/JPO-D-16-0089.1.

Forget, G., J.-M. Campin, P. Heimbach, C. N. Hill, R. M. Ponte, and C. Wunsch, 2015: ECCO version 4: An integrated framework for non-linear inverse modeling and global ocean state estimation. Geosci. Model Dev., 8, 3071-3104, https:// doi.org/10.5194/gmd-8-3071-2015.

Gray, A. R., and S. C. Riser, 2014: A global analysis of Sverdrup balance using absolute geostrophic velocities from Argo. J. Phys. Oceanogr., 44, 1213-1229, https://doi.org/10.1175/ JPO-D-12-0206.1.

Hautala, S. L., D. H. Roemmich, and W. J. Schmitz, 1994: Is the North Pacific in Sverdrup balance along $24^{\circ} \mathrm{N}$ ? J. Geophys. Res., 99, 16041-16 052, https://doi.org/10.1029/94JC01084.

Hogg, N. N. G., R. S. R. Pickart, R. M. R. Hendry, and W. J. Smethie, 1986: The northern recirculation gyre of the Gulf Stream. Deep-Sea Res., 33, 1139-1165, https://doi.org/10.1016/ 0198-0149(86)90017-8.

Holland, W. R., 1972: Baroclinic and topographic influences on the transport in western boundary currents. Geophys. Fluid Dyn., 4, 187-210, https://doi.org/10.1080/03091927208236095.

Hughes, C. W., 1995: A warning about topography in the Cox code. Ocean Modell., 106, 8-15.

- 2000: A theoretical reason to expect inviscid western boundary currents in realistic oceans. Ocean Modell., 2, 73-83, https://doi.org/10.1016/S1463-5003(00)00011-1.

__ , and B. A. de Cuevas, 2001: Why western boundary currents in realistic oceans are inviscid: A link between form stress and bottom pressure torques. J. Phys. Oceanogr., 31, 2871-2885, https://doi.org/10.1175/1520-0485(2001)031<2871: WWBCIR $>2.0 . \mathrm{CO} ; 2$.

Jackson, L., C. W. Hughes, and R. G. Williams, 2006: The role of bottom pressure torques and friction in basin and channel flows. J. Phys. Oceanogr., 36, 1786-1805, https://doi.org/ 10.1175/JPO2936.1.

Kelly, K. A., S. Singh, and R. X. Huang, 1999: Seasonal variations of sea surface height in the Gulf Stream region. J. Phys. Oceanogr., 29, 313-327, https://doi.org/10.1175/1520-0485(1999)029<0313: SVOSSH $>2.0 . \mathrm{CO} ; 2$.

Kwon, Y. O., M. A. Alexander, N. A. Bond, C. Frankignoul, H. Nakamura, B. Qiu, and L. A. Thompson, 2010: Role of the Gulf Stream and Kuroshio-Oyashio systems in large-scale atmosphere-ocean interaction: A review. J. Climate, 23, 32493281, https://doi.org/10.1175/2010JCLI3343.1.

Le Bras, I. A., 2017: Dynamics of North Atlantic Western Boundary Currents. Ph.D. thesis, Massachusetts Institute of Technology-Woods Hole Oceanographic Institution Joint Program, 174 pp., https://doi.org/10.1575/1912/8657.

_ , S. R. Jayne, and J. M. Toole, 2018: The interaction of recirculation gyres and a deep boundary current. J. Phys. Oceanogr., 48, 573-590, https://doi.org/10.1175/JPO-D-17-0206.1.

Leetmaa, A., P. Niiler, and H. Stommel, 1977: Does the Sverdrup relation account for the mid-Atlantic circulation. J. Mar. Res., 35, 1-10. 
Lu, Y., and D. Stammer, 2004: Vorticity balance in coarseresolution global ocean simulations. J. Phys. Oceanogr., 34, 605-622, https://doi.org/10.1175/2504.1.

Mertz, G., and D. G. Wright, 1992: Interpretations of the JEBAR term. J. Phys. Oceanogr., 22, 301-305, https://doi.org/10.1175/ 1520-0485(1992)022<0301:IOTJT>2.0.CO;2.

Munk, W. H., 1950: On the wind driven ocean circulation. J. Meteor., 5, 36-43, https://doi.org/10.1016/S0146-6291(58) 80006-5.

- , and E. Palmén, 1951: Note on the dynamics of the Antarctic Circumpolar Current. Tellus, 3, 53-55, https://doi.org/10.3402/ tellusa.v3i1.8609.

Palter, J. B., M. S. Lozier, and R. T. Barber, 2005: The effect of advection on the nutrient reservoir in the North Atlantic subtropical gyre. Nature, 437, 687-692, https://doi.org/10.1038/ nature 03969

Pérez-Hernández, M. D., G. D. McCarthy, P. Vélez-Belchí, D. A. Smeed, E. Fraile-Nuez, and A. Hernández-Guerra, 2015: The Canary Basin contribution to the seasonal cycle of the Atlantic Meridional Overturning Circulation at $26^{\circ} \mathrm{N}$. J. Geophys. Res. Oceans, 120, 7237-7252, https://doi.org/ 10.1002/2015JC010969.

Rhines, P. B., and W. R. Young, 1982: Homogenization of potential vorticity in planetary gyres. J. Fluid Mech., 122, 347-367, https://doi.org/10.1017/S0022112082002250.

Rienecker, M. M., and Coauthors, 2011: MERRA: NASA's Modern-Era Retrospective Analysis for Research and Applications. J. Climate, 24, 3624-3648, https://doi.org/10.1175/ JCLI-D-11-00015.1.

Risien, C. M., and D. B. Chelton, 2008: A global climatology of surface wind and wind stress fields from eight years of QuikSCAT scatterometer data. J. Phys. Oceanogr., 38, 23792413, https://doi.org/10.1175/2008JPO3881.1.

Rivière, G., and I. Orlanski, 2007: Characteristics of the Atlantic storm-track eddy activity and its relation with the North Atlantic Oscillation. J. Atmos. Sci., 64, 241-266, https://doi.org/ 10.1175/JAS3850.1.

Rossby, T., C. Flagg, and K. Donohue, 2010: On the variability of Gulf Stream transport from seasonal to decadal timescales. J. Mar. Res., 68, 503-522, https://doi.org/10.1357/ 002224010794657128.

Sato, O. T., and T. Rossby, 1995: Seasonal and low frequency variations in dynamic height anomaly and transport of the Gulf Stream. Deep-Sea Res. I, 42, 149-164, https://doi.org/ 10.1016/0967-0637(94)00034-P.

Schmitz, W. J., J. D. Thompson, and J. R. Luyten, 1992: The Sverdrup circulation for the Atlantic along $24^{\circ} \mathrm{N}$. J. Geophys. Res., 97, 7251-7256, https://doi.org/10.1029/92JC00417.

Schoonover, J., and Coauthors, 2015: North Atlantic barotropic vorticity balances in numerical models. J. Phys. Oceanogr., 1, 289-303, https://doi.org/10.1175/JPO-D-15-0133.1.

Schott, F. A., and R. Zantopp, 1985: Florida current: seasonal and interannual variability. Science, 227, 308-311, https://doi.org/ 10.1126/science.227.4684.308

- , T. N. Lee, R. Zantopp, F. A. Schott, T. N. Lee, and R. Zantopp, 1988: Variability of structure and transport of the Florida Current in the period range of days to seasonal. J. Phys. Oceanogr., 18, 1209-1230, https://doi.org/10.1175/ 1520-0485(1988)018<1209:VOSATO>2.0.CO;2.
Sonnewald, M., C. Wunsch, and P. Heimbach, 2019: Unsupervised learning reveals geography of global ocean dynamical regions. Earth Space Sci., 6, 784-794, https://doi.org/ 10.1029/2018EA000519.

Stammer, D., M. Balmaseda, P. Heimbach, A. Köhl, and A. Weaver, 2016: Ocean data assimilation in support of climate applications: Status and perspectives. Annu. Rev. Mar. Sci., 8, 491-518, https://doi.org/10.1146/annurevmarine-122414-034113.

Stommel, H., 1948: The westward intensification of wind-driven ocean currents. Eos, Trans. Amer. Geophys. Union, 29, 202206, https://doi.org/10.1029/TR029i002p00202.

Sutton, R. T., and B. Dong, 2012: Atlantic Ocean influence on a shift in European climate in the 1990s. Nat. Geosci., 5, 788792, https://doi.org/10.1038/ngeo1595.

Sverdrup, H. U., 1947: Wind-driven currents in a baroclinic ocean; With application to the equatorial currents of the eastern Pacific. Proc. Natl. Acad. Sci. USA, 33, 318-326, https:// doi.org/10.1073/pnas.33.11.318.

Thomas, M. D., A. M. De Boer, H. L. Johnson, and D. P. Stevens, 2014: Spatial and temporal scales of Sverdrup balance. J. Phys. Oceanogr., 44, 2644-2660, https://doi.org/10.1175/ JPO-D-13-0192.1.

Thurnherr, A. M., 2010: A practical assessment of the errors associated with full-depth LADCP profiles obtained using Teledyne RDI workhorse acoustic Doppler current profilers. J. Atmos. Oceanic Technol., 27, 1215-1227, https://doi.org/ 10.1175/2010JTECHO708.1.

Waterman, S., and S. R. Jayne, 2012: Eddy-driven recirculations from a localized transient forcing. J. Phys. Oceanogr., 42, 430447, https://doi.org/10.1175/JPO-D-11-060.1.

Wunsch, C., 2011: The decadal mean ocean circulation and Sverdrup balance. J. Mar. Res., 69, 417-434, https://doi.org/ 10.1357/002224011798765303.

, and D. Roemmich, 1985: Is the North Atlantic in Sverdrup balance? J. Phys. Oceanogr., 15, 1876-1880, https://doi.org/ 10.1175/1520-0485(1985)015<1876:ITNAIS > 2.0.CO;2.

, and P. Heimbach, 2007: Practical global oceanic state estimation. Physica D, 230, 197-208, https://doi.org/10.1016/ j.physd.2006.09.040

—, and — 2013a: Dynamically and kinematically consistent global ocean circulation and ice state estimates. Ocean Circulation and Climate: A 21st Century Perspective, G. Siedler et al., Eds., International Geophysics Series, Vol. 103, Academic Press, 553-580.

$\longrightarrow$, and,$- 2013 \mathrm{~b}$ : Two decades of the Atlantic meridional overturning circulation: Anatomy, variations, extremes, prediction, and overcoming its limitations. J. Climate, 26, 71677186, https://doi.org/10.1175/JCLI-D-12-00478.1.

Wyrtki, K., 1974: Equatorial currents in the Pacific 1950 to 1970 and their relations to the trade winds. J. Phys. Oceanogr., 4, 372-380, https://doi.org/10.1175/1520-0485(1974)004<0372: ECITPT $>2.0 . \mathrm{CO} ; 2$.

Yeager, S., 2015: Topographic coupling of the Atlantic overturning and gyre circulations. J. Phys. Oceanogr., 45, 1258-1284, https://doi.org/10.1175/JPO-D-14-0100.1.

Zhao, J., and W. Johns, 2014: Wind-driven seasonal cycle of the Atlantic meridional overturning circulation. J. Phys. Oceanogr., 44, 1541-1562, https://doi.org/10.1175/JPO-D-13-0144.1. 